\title{
UNIÃO ESTÁVEL OU UNIÃO INSTÁVEL?
}

\author{
Eduardo Carlos Bianca Bittar \\ Professor Associado do Departamento de Filosofia \\ e Teoria Geral do Direito da Faculdade de Direito \\ da Universidade de São Paulo.
}

\section{Resumo:}

A presente investigação reúne elementos históricos, éticofilosóficos e jurídicos para discutir como as transformações registradas pelo Direito de Familia incorporam mudanças valorativas reveladoras da criação de uma nova identidade, agora pós-moderna, garantidoras da diferença, da heterogeneidade e da pluralidade, como condições para a própria planificação da idéia de cidadania universal.

\section{Abstract:}

The present inquiry congregates historical, ethical-philosophical and legal elements to discuss how the transformations registered for the Family Law incorporate the changes revealing of creation of a new identity, now postmodern, warranting of the difference, the heterogeneity and the plurality. as conditions for the idea of universal citizenship.

Unitermos: Pós-Modernidade; Direito de Familia; moralidade social; transição paradigmática.

Keywords: Post-modemity; Family Law: Social morality; paradigmatic transition.

Sumário: 1. Introdução; 2 . Mudanças de hábitos e efeitos sociais: rastreando a pósmodernidade; 3. Transformações da ética familiar na pós-modernidade; 4. O Direito de Familia em mutação; Conclusões; Bibliografia.

"Em nosso mundo de furiosa 'individualização os relacionamentos são bençãos ambigüas. Oscilam entre o sonho e o pesadelo, e não há como determinar quando um se transforma no outro" (Bauman, Amor liquido: sobre a fragilidade dos laços humanos, 2004, p. 08). 


\section{Introdução}

Esta reflexão parte de uma evidència: o Direito de Família sofreu nos últimos anos uma avalanche de mudanças, inomináveis do ponto de vista histórico, e cuja significação ultrapassa a capacidade de redução. Poder-se-ia, por exemplo. dizer que o que está ocorrendo é fruto de um processo de "conquista de direito" de "aumento do espaço de liberdades" ou mesmo, que se trata de uma "ampliação das visões de mundo sobre a familia" Nenhuma destas visões seria suficientemente descritiva do que se produz em meio às complexidades sociais. Tudo isto, em suma. nos propõe o espaço da investigação reflexiva. para que se some às impressões subjetivas da realidade uma visãu que procura delinear as transformações do Direito de Família em meio a uma enormidade de outras transformações sócio-axiológicas. Trata-se de apontar como linha investigativa ao tratamento desta complexa malha de mudanças sociais o estudo da 'transição paradigmática' expressão cunhada por Boaventura de Souza Santos, como significando uma passagem (tensa, ambígüa. complexa, divergente, repleta de idas e vindas) do moderno ao pós-moderno.

Esta discussão leva em consideração que os tempos que ora correm sob nossus olhos representam uma passagem da cultura do homogêneo (cultura ainda não totalmente diluída) em direção a uma cultura do heterogèneo (cultura ainda não completamente consolidada), ' e, não simplesmente uma superação temporal do moderno pelo pós-moderno, como sendo o retrato de um evolucionismo histórico que não se entende cabivel para a descrição do fenômeno. Quando se pergunta sobre o pós-moderno, deve-se identificar por este termo nada mais que uma vaga de mudanças que não pode ser resumida simplesmente por descrições simplificadoras aus níveis da moral. da política ou da cultura; trata-se de um amplo espectro de mudanças. que afeta vários niveis de organização da vida contemporânea,

I. Sobre a identidade do pós-moderno cum o heterogêneo: "El Derecho postmoderno no puede ser construido en términos que impliquen una reducción forzada a la unidad sino como la posibilidad de articular las diferencias, de mostrar las afiliaciones sin perder la heterogeneidad. Tiene que ser un orden juridico esencialmente 'dinámico: no puede pretender fijar la sociedad de una determinada manera, no es una-plantilla que se aplica sobre la riqueza de la vida social para que ésta se comporte en patrones conocidos (...)" (p. |02); "El jurista postmoderno debe, entonces, estar atento a las derivaciones, bifurcaciones, distinciones, dispersiones, fijarse no solo en la regla sino también en las excepciones, no solo en la conducta regular sino también en la irregular, tiene que revalorar la informalidad, escuchar las múltiples voces que se expresan en la sociedad" (Granda, Postmodernidad y derecho. 1993, p. 103). 
determinando novas consciências e modos de agir no mundu. ${ }^{2}$ Isto basta para motivar esta investigação sobre a projeção destas circunstâncias sobre a dimensão dos relacionamentos afetivos $\mathrm{e}$ as estruturas socialmente institucionalizadas de organização da família.

O que se vive, de fato, são novas situações-limite, todas desafiadoras. registradas como mudanças, inovações, recriações, num entrechoque de instâncias valorativas por vezes conciliáveis, por vezes antagônicas, especialmente considerada a expansão da consciência microcósmica de direitos fundamentais da pessoa humana (minorias, mulheres, crianças, idosos, deficientes, consumidores, etc.) todas incorporadas pela legislação e todas igualmente protegidas pelo ordenamento juridico (sendo o cerne de não-esporádicas antinomias e paradoxos do sistema legislado brasileiro).

O que se haverá de desafiar enquanto tema de discussão e debate ao longo desta investigação é de que modo esta enormidade de transformações sócioculturais afeta direta e indisfarçavelmente o universo axiológico fundante do Direito de Familia brasileiro, especialmente de um Direito de Família herdado do Código Civil, de 1916, este que foi gestado sob o manto de imperativos morais que hoje vivem o conflito e a instabilidade de uma humanidade lançada na condição pósmoderna.

2. Mudanças de hábitos e seus efeitos sociais: rastreando a pós-modernidade

A vida contemporânea está reccheada de eventos que marcam a identidade (diluída, líquida. amorfa) de um tempo, este que se tem costumado chamar de pós-moderno. Neste iter cultural, o que está em voga é uma cultura da

2. Esta concepção se extrai de Gilles Lipovcstky: "Post-modeme: à tout le moins. la notion n'est pas claire, qui runvoie à des niveaux ut sphères d'analyse difficiles parfois à faire coïncider. Epuisement d'une culture hédoniste et avant-gardiste ou surgissement d'unc culture hédoniste et avant-gardiste ou surgissement d'une nouvelle puissance novatrice? Décadence d'une époque sans tradition ou revitalisation du présent par une réhabilitation du passé? Continuití nouvelle manière dans la trame moderniste ou discontinuité? Péripétie dans l'histoire de l'art ou destin global dês sociétés démocratiques? Nous avons refusé ici de circonscrire le post-modernisme dans um cadre regional. esthétique, épistémologique ou culturel: si apparaît unc post-modernité. celle-ci doit designer tme vaguc profonde et générale à l'échelle du tout social. puisqu'il est vrai nous vivons um temps où les uppositions rigides s'estompent, où lês prépondérances deviennent floues, ou l'intelligence du moment exige la mise em relief des corrélations et humulogies" (Gilles Lipovetsky, L'ère du vide: e'ssais sur l'individualisme contemporain. 1983, p. 113-114). 
emancipação do ego, ${ }^{3}$ vivida de um modo tão intenso que se redefinem as concepções de vida a partir deste epicentro. De fato, o individualismo contemporâneo é uma espécie de marco da definição dos papéis sociais, das formas de fruição do mundo, dos modelos de ação, dos paradigmas sociais, dos desejos coletivos, das projeções de esperança da psicologia social, etc. de modo a agir sobre as mentalidades a ponto de definir novas condições de vida, novas práticas sociais, novas identidades culturais, gestando e cristalizando novos valores na esfera do convivio humano.

Trata-se de verificar como se trata de um tempo sem congênere maior, e, portanto, de um tempo onde as marcas do individualismo e das subjetividades diversificadas se definem de um modo tão acidental quanto as opções possívcis (todas válidas e adotáveis) de vida, indefinidas em sua abertura, mas capazes de conviver na diferença. A regra é: não há regra. Il n y a pas de règle, diriam os franceses. ${ }^{4}$

Há pressões diluidas em fornalhas de criação do ideário social que tornam o individuo pós-moderno (diluido, líquido, amorfo, apático, como seu tempo) a caixa de ressonância de diversas eras. diversas tendências, diversas formas de compreensão de mundo, diversas exigências morais e sentimentais, etc. Tudo permite que se projete sobre ele um conjunto de exigências suficientes para criarem uma pressão contínua em torno do ser ou não-ser capaz de responder a todas as demandas externas, aumentando o grau de complexidade das decisões estabilizadoras da personalidade. O que se é na pós-modernidade deixou de ser uma pergunta simples para a qual se possa encontrar uma resposta fácil. $O$ individuo pós-moderno é um ser ubiquo, ${ }^{5}$ na medida em que ocupa muitos lugares no mundo, inclusive alguns díspares

3. Segundo Lipovetsky: "La culture post-moderne est du feeling et de l'émancipation individuelle élargie à toutes les categories d'àge et de sexe" (I ipovetsky, L'ère du vide: essais sur l'individualisme contemporain, 1983, p. 32).

4. O registro da identidade desta época é: "Le moment post-moderne est bien davantage qu'une mode, il révèlc le procès de l'indifférence purc en ce que tous les goûts, tous lês comportements peuvent cohabiter sans s'exclure, tout peut être choisi à loisir, le plus opérationnel comme le plus ésotérique, le nouveau comme l'ancien, la vie simple-écologiste comme la vie hypersophistiquéc. dans um temps dévitalisé sans repère stable. sans coordonnée majeure" (I.ipovetsky, L'ère du vide: essais sur l'individualisme contemporain, 1983, p. 58).

5. O termo vem da reflexão de Gilles Lipovetsky: "On peut ainsi être simultanément cosmopolite et régionaliste. rationaliste dans son travail et disciple intermittent de tel gourou oriental, vivre à l'heure permissive et respecter, à la carte d'ailleurs, les prescriptions religieuses. I. 'individu post-modeme est destabilizé, il est en quelque sorte <<ubiquiste $>$. Le post-modernisme n'est en fait qu'un cran supplémentaire dans l'escalade de la personnalisation de l'individu vouć un self-service narcissique et aux combinaisons kaléidoscopiques indifférentes" (Gilles Lipovetsky, L'ère du vide: essais sur l'individualisme contemporain. 1983, p. 59). 
e contraditórios entre si, a fím de satisfazer às exigências de seu tempo, questão esta que abeira o nivel da sobrevivência (material, econômica, social, psicológica, etc.).

Para além do fato de toda esta convergência de pressões multiplicarem o espaço da indecisão, da despersonalização, do conflito moral, exacerbando a incapacidade de entendimento e compreensão das relações intrasubjetivas e intersubjetivas, ou seja, além de gerar dificuldades ético-comportamentais e conflitos psicanalíticos, ${ }^{6}$ tudo isto também culmina numa dificuldade mútua compreensão entre as pessoas (tendo em vista que não há limites para os comportamentos, tudo é possível; tendo em vista que não há estabilidade de comportamentos, qualquer coisa é lícita ao comportamento; tendo em vista que não há padrões estanques de moralidade social, estes que foram rompidos com os movimentos ocorridos no seio da pósmodernidade, o outro é sempre um estranho irreconhecivel). ${ }^{7}$ Os níveis de recrutamento do outro passam do nível da pré-aceitação ao nível da pré-desconfiança, determinando o estranhamento como critério de construção dos intercâmbios humanos e sócio-culturais.

A hiperindividualidade, para usar uma linguagem de Lipovetsky, é a marca deste tempo, excessivamente descolado da capacidade de oferecer modelos unânimes ou concepções de mundo universais. O quadro apresentado, portanto, descreve, por uni-termos, o universo das transformações sofridas ao longo das últimas décadas e que afetam diretamente os modelos sociais vigentes, determinando resultados sócio-comportamentais dirigidos conforme novos paradigmas. Em última instância, esta conjuntura acima descrita permite projetar tensões históricas para a dimensão da estabilidade familiar, tornando-as ora administráveis, ora inadministráveis.

Presentemente, o que se tem é não-só um choque de gerações e universos de valores se processando, mas sobretudo o aparecimento de uma nova geração, cultivada sob a insignia do contexto pós-moderno, e, portanto, erigida sob a marca destes tempos; esta seria a primeira geração efetivamente marchetada por esta vivência, fruidora que é de uma série de benefícios oriundos dos avanços da ciência, da tecnologia e do conforto, do mesmo modo como já está sendo a geração que

6. O tema é tratado pelo psicanalista Jorge l:orbes (Você quer o que deseja?, 2003).

7. Se dizia mesmo que é proibido proibir: "On disait <<il est interdit d'interdire»>"(Gilles Lipovetsky, L'ère du vide: essais sur l'individualisme contemporain, 1983, p. 317). 
suporta os efeitos de tempos que não foram criados por seus indivíduos, mas cujo saldo (positivo e negativo) de diversas revoluções ocorridas historicamente ao longo das últimas décadas (revolução tecnológica, revolução feminina, revolução sexual, revolução dos costumes, revolução estudantil, revolução juvenil, revolução da moda, revolução dos padrões religiosos...), deverá ser administrado pelo quociente de capacidades de adaptação ao choque de valores de gerações que acabaram por desenvolver. Trata-se de avaliar o quanto as biografias se torcem e retorcem para atender a condições de vida cada vez mais complexas.

Sem dúvida, a administração desta complexidade de fatores torna mais tensa a estabilidade das relações afetivas, com repercussões claras na institucionalização e no estatuto destas relações, na medida em que os valores em convívio são muitas vezes ingredientes que direcionam a vontade para muitas perspectivas (vontade de liberdade, conflitante com a vontade de felicidade, sendo ambas conflitantes com a vontade de realização profissional, etc.), quando então decidir pela própria estabilidade se torna difícil. Muitas vezes, a coexistência de valores divergentes induz à negação de valores (por vezes, anteriormente consensuais), tencionando e causando disparidades na eleição de valores. ${ }^{8}$

Vive-se, portanto, mais que tudo, numa sociedade do medo (medo da traição, medo da violência, medo do roubo, medo do golpe, medo da inflação, medo da queda do governo, medo do plano monetário, medo da traição societária...), de um medo permanente, que está sempre à espreita, fator este que acaba projetando uma série de neuras hiperindividualizantes, capazes de construírem uma nova lógica das relações intersubjetivas, assim como, em última instância, também das relações afıtivas: laços esporádicos, com o minimo de comprometimento possível, com um grau de parceria reduzido, capaz de gerar no máximo uma espécie de união instável, conveniente enquanto dura e enquanto é capaz. de gerar maior conforto físico-sexual

8. Não pode ser outra a conclusão, senão: Essas mudanças sociais e culturais interferiram na vida da família. A família tradicional arcaica, que se afirmou no contexto da cultura rural, entrou em crise. Os modelos de comportamento que regulamentavam as relaçōes entre os sexos e as relações de patemidade, maternidade, filiaçäo tornaram-se obsoletos e foram abandonados. Em breve tempo, entrou em crise também a "lamilia nuclear" urbana, que deveria constituir a forma mais adequada de resposta às exigências da sociedade moderna. Ao mesmo tempo, todas as formas de respostas alternativas que foram tentadas não oferecem soluções satisfatórias. Como conseqüência disso, as novas gerações encontram. atualmente mais dificuldades para alcançar a estabilidade psicológica, necessária para enfrentar os desafios da existência na sociedade moderna" (Petrini, Pós-modernidade e familia: um itinerário de compreensão. 2003, p. 42). 
(certa estabilidade sexual), afetivo-emocional (certa estabilidade emocional) e material-estrutural (certa estabilidade relacional, financeira e juridica) aos parcciros de relação."

Mas, o amor à estabilidade não é maior, e cede quando o inconveniente surge (daí a fugacidade dos relacionamentos hodiernos), que o amor à liberdade (aos compromissos sexuais fluidos e passageiros, às facilidades do convívio na vida contemporânea, à não-intervenção do outro sobre os domínios de sua vida, à liberdade de trabalhar em outro pais ou estado se isto é necessário, etc.). Daí se verificar o nascimento de diversas formas de conjugação de interesses que não chegam a se solidificar em esponsais ou matrimônios (casais onde cada qual mora em sua casa, mas se vîem aos finais de semana; casais que vivem vidas paralelas, sob convívio, cada qual possuindo inclusive vidas econômicas e jurídicas autônomas, tendo conta corrente, dinhciro e negócios plenamente individidualizados, etc.), o que obviamente, $\mathrm{cm}$ última instância, se traduz em novos comportamentos à latere da legislação matrimonial clássica (centrada no ritual do casamento civil), tornando novamente desafiador controlar direitos dentro de relações afetivas cada vez mais determinadas pela informalidade de sua existência, pelo individualismo dos papéis, pela fugacidade de sua duração.

Ora, uma sociedade cuja marca é o medo (a inscgurança) acaba por introjetar para dentro do quotidiano de vida de scus indivíduos a lógica do medo afinal, quem é este outro (estranho) que está ao meu lado"? na estruturação dos relacionamentos afetivos, presentes e futuros (casais que, por mais que se gostem e confiem, mantêm seus segredos, suas senhas, scus códigos, suas contas escondidas; casais que, por mais que depositem fé na conduta do outro, casam em condição de scparação total de bens). A lógica do medo é, sem dúvida alguma, corroborada, especialmente quando se é consabido que a tutela a Direitos de Familia pode resultar em catastróficos cinco ou dez anos de disputas no Poder Judiciário, de modo que o ceticismo quanto à segurança jurídica decorrente das relações afetivas acaba por

9. "Na sociedade moderna, muitas vezes, parcce mais decisivo, para a própria realização pessoal, crescer na carreira profissional, dando mais importância às rulações funcionais que se caracterizam pela competiçào individualista e tendem a favorecer a fragmentação da pessoa. Além disso, difunde-se uma sunsibilidade que considera qualquer vínculo como uma amarra mortificante. parecendo desejável ficar livre de qualquer relacionamento mais profundo" (Petrini. Pós-modemidade e familia: um itinerário de compreensãu, 2003, p. 73 e 74). 
resultar em maior descrença em relações onde os parceiros são altamente compromissados, dedicados e leais. De fato, nesta hipótese, reafirma-se a necessidade de precaução juridico-econômica do casal (prevenção forte), que se superpõe àquela outra da garantia e da decisão do afeto recíproco (prevenção fraca).

A lógica do medo é, sem dúvida alguma, uma espécie de ácido que corrói as relações morais, determinando a ética dos comportamentos, bem como o modus das relações afetivas hodiernas, o que leva ao estado fluido das relações afetivas no mundo pós-moderno. A figura dos indivíduos em rotação. ora em fuga (de um medo presente ou potencial), ora à procura de algo (concreto ou inindentificado), mas sempre em alta velocidade, ${ }^{10}$ é a melhor metáfora a exprimir a explosão de comportamentos dispares que geram a incompreensão mútua, o desaparecimento da capacidade de entendimento da alteridade, o estranhamento do outro como précondição das identidades recíprocas, com as demais resultantes daí decorrentes.

Aliás, este estado é mais que fluido. é frágil, é inseguro. é incerto, é indeterminado, é inconstante, é permeável, é elástico, é descompromissado, é nãolongevo. Eis os traços que haverão de marcar a dimensão da nova ética dos relacionamentos (homo- ou hetero-) afetivos.

Se esta é a regra, especialmente num mundo onde vale a materialização das relações humanas. onde se processa a coisificação do significado da dignidade da pessoa humana, onde predominam valores consumistas, onde se destacam precedentes de comportamentos focados na estética consumista, onde se criam identidades a partir da posse de certas condições de acesso a bens privilegiados de consumo, " então a rotação dos relacionamentos afetivos passa a observar a mesma química das relações de mercado. Como afirma Zygmunt Bauman:

"Guiada pelo impulso ('seus olhos se cruzam na sala lolada') a parceria segue o padrão do shopping e não

10. "Estar em movimento, antes um privílégio e uma conquista, torna-se uma neuessidade. Manterse em alta velocidade. antes uma aventura estimulante, vira uma tarcfa cansativa. Mais importante, a desagradável incerteza e a irritante confusão. supostamente escorraçadas pela velocidade, recusam-se a sair de cena" (Bauman, Amor liquido: sobre a fragilidade dos laços humanos. 2004, p. 13).

11. "E assim é nuina cultura consumista como a nossa, que favorece o produto pronto para uso imediato, o prazer passageiro, a satisfação instantânea. resultados que não exijam esforços prolongados, receitas testadas, garantias de seguro total e devoluçāo do dinheiro" (Bauman, Amor liquido: sobre a fragilidade dos laços humanos, 2004, p. 22). 
exige mais que as habilidades de um consumidor médio, moderalamente experiente. Tal como outros bens de consumo, ela deve ser consumida instantaneamente (não requer maiores treinamentos nem uma preparação prolongada) e usada uma só vez, sem preconceito É antes de mais nada, eminentemente descartável" (Bauman, Amor líquido: sobre a fragilidade dos laços humanos, 2004, p. 27).

3. Transformações da ética familiar na pós-modernidade

Em determinados momentos históricos especificos se acirram as mudanças que qualificam as condições de vida, a ponto de se tornarem visíveis, aos olhos do atento observador, a diluição de certos valores estanques, com a substituição ou a ascensão de outros, ou não. De qualquer forma, os sinais das transformações se dão aos poucos, e se fazem perceber paulatinamente na vida social. Este registro, de Karl Jaspers, denuncia isto, no início dos anos 60:

"Coloca-se em dúvida o valor da lealdade no casamento, na amizade, na vida profissional. Em todos os setores, o mesmo se afirma: a permanência deixa de existir, em nada mais é possivel confiar" (Jaspers, Introdução ao pensamento filosófico, 1971, p. 30).

Há sensíveis alterações dos modos de vida que passam a marcar a reconceituação das práticas intersubjetivas, culminando em novos arranjos de ações e comportamentos individuais tomados, isolada ou coletivamente, como diluidores dos paradigmas anteriores de vida.

A idéia de família, as relações de família. o conceito ao qual se identifica a formação de família, são todas concepções que têm sido revistas com tão permanente insistência que são capazes de despertar o olhar para as alterações em curso, a ponto de instigarem algum tipo de reflexão, em especial, dedicada a compreender o que se tem como práxis social. 
Sem dúvida, as axiologias em acomodação (entre duas gerações, entre tempos históricos diversos, em contextos de alta pluralidade cultural), além de incomodarem os valores assentidos e consensuados por gerações anteriores, permitem entrever o quanto a ausência de permanência incomoda a legalidade, a institucionalidade, a verticalidade, bem como a hegemonia de um modelo de família. Por isso, ainda com Jaspers, tem-se um panorama que remexe condições antes consideradas vitais da estrutura familiar da sociedade:

"O casamento é a ordenação das realidades sexuais e eróticas para criaçâo do universo da família, no qual surgem os filhos protegidos por esse universo. $O$ casamento reclama permanência. É elemento estrutural da sociedade.

"Os que amam desejam, na comunidade doméstica, modelar em conjunto o cotidiano; não aspiram a correr empós de aventuras novas ao sabor do momento. Desejam que a sociedade os reconheça como um casal.

"Dai surge a instituição legal, amparada pelo Estado. O casamento, bem precioso, é um dos milagres da História; é a ordem predominando sobre a sexualidade bruta, é o reconhecimento de obrigações entre os esposos e paru com os filhos" (Jaspers, Introdução ao pensamento filosófico, 1971, p. 119-120).

As mudanças na ética familiar estão a denunciar não-só que movimentos maiores de massas de valores sociais estão se acomodando ou se reconstruindo em um outro modelo (este que não se saber identificar ainda qual é), mas. sobretudo, que os princípios norteadores da estrutura anteriormente constituída, por vezes, só eram mantidos às custas de uma hegemonia axiológica reveladora de um status quo pouco flexível às alternativas, e, que, por vezes, a permanência era 
conseguida a partir da verticalização dos modelos sociais de estruturação da própria família.

Neste sentido. historicamente, é de se examinar que a cultura brasilcira possuía sua identidade cultural sobre o que fosse a família claramente delineada; era estruturada nos costumes sociais predominantes na cultura brasileira, significava a união de duas pessoas de sexos diferentes, cuja precípua finalidade era procriativa, obecendo a um esquematismo hierárquico na chefia dos costumes e decisões familiares concentrados na predominância do modelo patriarcal. tendo-se, portanto, como decorrência, um núcleo familiar orientado em torno de uma cultura homemcentrada (provinciana, machista inclusive pelas mulheres, tradicional e conservadora). 12

$\mathrm{Na}$ transição dos tempos. na passagem da modernidade à pósmodernidade, caminha-se de um modelo de sociedade machista (pai-orientada, tradicional, procriativa, provinciana, com papéis definidos) ${ }^{13} \mathrm{em}$ direção a uma sociedade liberal (aberta, plural, diversificada, destradicionalizada, com fusão de papéis). Esta última é efetivamente capaz de ostentar a condição de exercicio de uma ética da diversidade. superando a condição biológica na definição dos papéis relacionais. mas causando perturbações severas nos modos de compreensão dos modelos sociais. Não há dúvidas de que isto desagrega e gera crises, altera as condições de vida e determina o espectro das ações e posturas de indivíduos,

12. $\dot{E}$ evidente que o desaparecimento da predominância deste modelo causa severas crises: A família contemporânea passa por um momento de transição. São abandonados modelos "tradicionais", que atribuiam o primado ao marido, reservavam às mulheres tarefas preferencialmentc domésticas. pensavam a relação entre pais e filhos dentro de certa visão da autoridade e da disciplina. davam grande importância aos aspectos institucionais da convivência familiar. e assim por diante. Foram dados passos no sentido de criar novos padrões de comportamento nas relações familiares, no campo da sexualidade, da procriação, da paternidade e da maternidade. da relação entre pais e fillhos, do trabalho c da repartição das tarefas domésticas. Não se trata, agora, de olhar com saudades os modelos antigos de convivência familiar, mas de consolidar passos que constituam efetivamente um crescimento humano para todos os membrus da familia e para o grupo familiar no seu conjunto. (Petrini, Pós-modernidade efamilia: um itinerário de compreensão, 2003, p. 64).

13. "Por outro lado, a influência do pensamento marxista levou os grupos de esquerda a considerarem a familia como o lugar da reprodução de uma mentalidade conservadora, contrária a militância pulitica è à revolução. De modo semelhante, para boa parte da psicanálise, a familia parecia marcada pela suspeita de desempenhar uma função disciplinadora, responsável por transmitir principalmente modelos e valores contrários à renovação da sociedade e à revolução sexual. Foi criticada, de modo especial, a figura do pai, como autoridade e repressor" (Petrini, Pós-modernidade e familia: um itinerário de compreensão, 2003. p. 58). 
especialmente diante de seus novos papéis relacionais, mas não há dúvidas de que esta superação traz consigo uma leva enorme de mudanças favoráveis à ampliação do universo da valores vigentes no que tange à perspectiva dos relacionamentos.

Uma arqucologia dos porões dos valores familiares haveria de revelar. curtamente, uma submissão dos padrões axiológicos a uma ética biológica, que, atualmente, deixou de ser lida e interpretada como única marca identificadora dos papéis sociais. Isto significa, na perspectiva da mulher, um inconsciente coletivo produtor de uma cultura que acalentava a obediência ao modelo do homem-macho (racional, provedor, protetor e trabalhador, projetado para os espaços públicos), e, na perspectiva do homem, um inconsciente coletivo que acalentava uma cultura da mulher-ninho, afeita à gestação, à alimentação, ao cuidado dos fillhos, enfím. ao privado.

Isto é não-só sintoma da erupção de diversas transformações sociais simultâneas, especialmente se for admitida a idéia de que a família é a celula mater da sociedade, mas sobretudo da eclosão de uma ruptura com a homogeneidade moderna dos valores, unificados em normas igualizadoras . a pretexto de praticar-se igualdade na generalização abstrata das leis e dos códigos morais burgueses de controle do comportamento social.

Isto significa, ainda, uma mudança na compreensão do reciproco entendimento de que papéis compartilhados e reciprocos atendem de modo mais humano às condições específicas de cada indivíduo, agora alforriado da culpa de ser discrepante do modelo único-padrão que orienta as axiologias hegemônicas (nem todo homem precisa ser uma máquina racional-produtiva e provedora; nem toda mulher se realiza na função biológica, maternal e procriativa; nem toda familia para ser tal precisa ter filhos; etc.), ${ }^{14}$ estas garantidas pelos instrumentos de Estado,

14. De fato, os modelos de vida imperantes, bem como as necessidades cotidianas de vida. os padrões de consumo. o ritmo de trabalho. a triplicação da jornada dos pais são fatores que têm influenciado diretamente na decisão, agora racional e não mais sentimental ou biológica, de ter filhos (decisão sobre tê-los ou-não; decisão sobre a quantidade): "Os lilhos estão entre as aquisições mais caras que o consumidor médio pode fazer ao longo e loda a sua vida. Em termos puramente monctários, eles custam mais do que um carro luxuoso do ano, uma volta ao mundo em um cruzciro ou até mesmo uma mansão. Pior ainda, o custo total tende a crescer com o tempo, e seu volume não pode ser fixado de antemão nem estimado com algum grau de certeza"

"Tê-los ou-não í comprovadamente a decisão com maiores conseqüĉncias e de maior alcance que existe. e portanto também a mais angustiante e estressante" (Bauman, Amor liquido: sobre a fragilidade dos laços humanos, 2004, p. 60). 
especialmente por aqueles que foram cunhados ao longo da modernidade para serem garantidores de homogeneidade axiológica (igualdade, universalidade, impessoalidade).

De certa forma, uma conclusão desde já é possível: a enxurrada de mudanças neste campo da organização dos valores familiares está a apontar para a insuficiência dos modelos modernos de regulação e controle das relações familiares e afetivas. Isto porque se está instalada historicamente uma verdadeira tensão bipolar, centrando forças concorrentes e antagônicas; de um lado, a lei falando a linguagem das grandes instituições sociais (fruto de uma cultura pai-orientada pelo Estado), e, de outro lado, as forças axiológicas e as práticas sociais desenvolvendo alternativas de comportamento sustentadoras de valores não-coincidentes com o modelo rigoroso e padronizado pelas instituições. É exatamente este cenário cultural que cria uma espécie de confrontu dialético, onde se opõem as forças centrípetas do Direito hegemúnico e do Estado onipresente em face das forças dos contra-modelos microuniversais que se distribuem como movimento centrífugo deste maquinário de definições que preenchem os movimentos do inconsciente coletivo. Re-ler estes tempos é. no mínimo. desafiador.

4. O Direito de Família em mutação

É certo que o conjunto destas modificações haveria de afetar de modo direto o sistema jurídico nacional, em especial aquele sistema especifico relacionado ao Direito de Família, esta que é a parte mais sensível às mudanças axiológicas, morais, geracionais, de modo a estar sujeita a variáveis sócio-culturais e antropológicas (compreensão do sentido da sexualidade, das questões de gênero, das diferenças funcionais entre os sexos, hierarquização das relações humanas, etc.) que têm uma capacidade de sobredeterminar este sistema de regras jurídicas (é notória a diferença paradigmática dos prescritivos sobre o nome de casado na codificação de 1916 - art. 240, parágrafo único: "A mulher poderá acrescer aos seus os apelidos do marido" - e na atual codificação - art. 1.565, parágrafo $1^{\circ}$ : "Qualquer dos nubentes. querendo, poderá acrescer ao seu sobrenome do outro"). O Direito de Família, como ramo do Direito Privado, torna-se, então, objeto de atenta análise da própria vivência da pós-modernidade, na medida em que se torna tema privilegiado de análise no contexto de discussões acerca do direito civil na pós-modernidade. 
As simultâneas crises - onde o termo 'crisc' é entendido como sinônimo de transformação transitiva - que afetam a compreensão valorativa do mundo (clonagem humana, dircito ao aborto de letos anencéfalos, bebês sob encomenda laboratorial, reprodução assistida, fertilização 'in vitro', barriga de aluguel, filiarquização das relações familiares, etc.) ${ }^{15}$ inquestionavilmente se reproduzem a ponto de fazer com que o Direito de Família seja afetado por transformações avassaladoras nas concepções tradicionais de família, ${ }^{16}$ e de seu sentido social. ${ }^{17}$ A própria idéia de institucionalizar um relacionamento, e, portanto, dotar-lhc de ciência pública e notória, ao mesmo tempo que permanente, encontra-se destituida de sentido, afinal, com Bauman, pode-se constatar:

"Afinal, a definição romântica do amor como 'até que a morte nos separe está decididamente fora de moda, tendo dcixudo para trás seu tempo de vida útil cm função da radical alteração das estruturas de parentesco às quais costumava servir e de onde exiraía seu vigor e sua valorização" (Bauman, Amor liquido: sobre a fragilidade dos laços humanos, 2004, p. 19).

15. No mesmo sentido: "As novas tecnologias de fecundação artificial, clonação e de manipulação genética apresentam novas questões, ainda $\mathrm{em}$ debate, cabendo aprofundar não apenas os aspectos médicos e psicológicos, mas também éticos e morais" (Petrini, Pós-modernidade e fomília: um ifmeráio de compreensão, 2003, p. 74).

16. "De outro lado, relações estáveis nascem de um projeto partilhado de vida, alimentado pela reciproca doação, configurando uma aliança esponsal. Estas últimas relações procuram legitimar-se com a celebração do matrimônio, civil e/ou religioso, constituem uma familia, aberta à geração e à educação de filhos, sendo marcadas por um compromisso recíproco de fidelidade entre os cônjuges que. pelo menos na intenção, deverá durar até que a morte os separe. Neste caso, a relação assume uma importância decisiva para definir a identidade das pessoas envolvidas".(Petrini, João Carlos. Pósmodernidad: e familia: um itinerário de compreensão, Bauru, SP: EDUSC, 2003. p. 70).

17. Veja-se esta entrevista: "A promotora de justiça Myriam Vasconcellos de Souza acredita que o aumento do númcro de separações e divórcios deve-se, por um lado, ao fato de muitas mulheres terem conquistado a independência financeira e obtido meios para se livrarem de um casamento já muito prejudicial a elas. Por outro lado, o individualismo vem prevalecendo e o nível de compreensão aos outros diminuindo. "As pessoas não se suportam mais. Não existe muita tolerância", disse Myriam" (Casamento e família. Entrevistas, Revista do Movimento do Ministério Público Democrático, ano 1, n. 03, 2004, p. 20). 
O que ocorre é que o sistema de regras jurídicas que regem as relações familiares se ressente de uma mutabilidade que recorre ao mesmo espectro fenomênico dos fatos e valores em curso, de modo a que as transformações importam em ajustes não-conhecidos ou não-aceitos pelo sistema oficial. Nem o sistema oficial de direito, rígido e garantidor da 'segurança jurídica', é suficientemente flexível para acompanhar a velocidade das mudanças sociais dos últimos trinta anos, nem os comportamentos sociais se convertem tão facilmente às exigências do sistema legal oficial de Estado. Tudo isso pode apontar para um não-modelo oficial (o que é improvável) ${ }^{18}$ ou para o reconhecimento de muitos modelos de família afastados do modelo burguês-monogâmico-paternalista-heterossexual (o que parece já ter começado a ocorrer).

A conseqüência disto é que a última década ${ }^{19}$ de transformações no direito de família foi coalhada por revisões, reformas e renovações do sistema legislativo - todas insuficientes - regulamentando o setor com contradições que têm sido apontadas pela dogmática jurídica civilista (leis da união estável, movimentos sociais de GLS's, novo código civil). Aliás, a história jurídica destas mudanças se vem se acentuando ao longo do século XX acompanhando exatamente o fluxo das conquistas axiológicas ao longo deste tempo vividas. Partiu-se, portanto, de um Código Civil (1916) machista, centrado no pátrio-poder, ruralista e estritamente centrado na lógica da defesa da propriedade privada (e, em especial, do latifúndio brasileiro), passando-se pela entrada das mulheres no âmbito da cidadania, a partir de 1932, com o direito ao voto, bem como pela consagração, em 1948, da igualdade de sexos, para exsurgir somente em 1962 o Estatuto da mulher casada, e em 1977, a Lei do Divórcio.

A Constituição Federal de 1988, por sua vez, consagra a idéia de igualdade como sendo um direito humano fundamental, fazendo distinções essenciais

18. Dai a pergunta: "Para muitos o casamento é uma instituição falida, sendo crescentc o número de divórcios e de uniões estáveis. Será que não haverá mais casamento no futuro?" (Casamento c familia. Fntrevistas, Revista do Movimento do Ministério Público Democrático. ano I, n. 03. 2004, p. 20).

19. Scria coincidência que a referida década é exatamentc aquela em quc a taxa de nupcialidade se reduziu em função de modificaçòes sociais? Registram-se atualmente aproximados 180 mil casamentos/ano: "No Brasil, a taxa de nupcialidade caiu durante toda a década de 90 e se estabilizou entre 2001 e 2002. Em 1991 foram registradas 7,5 uniões legais a cada mil habitantes, caindo para 5,7 em 2001, 2002" (Casamento e familia. Entrevistas, Revista do Movimento do Minístério Público Democrálico, ano 1, n. 03, 2004, p. 20). 
para o tratamento diferenciado dos gêneros, além de utilizar-se da expressão 'união estável' pela primeira vez na histórica do direito brasileiro (art. 226, parágrafo $3^{\circ}$ da ('F 88), para que, ao longo da década de noventa a regulamentação da união estável trouxesse suas polêmicas (Lei n. 8.971/94, que regulamenta a união estável; Lei n. $9.278 / 96$, que define a união estável). No que tange à união estável, tratava-se, a um só tempo de regulamentar a Constituição, através de legislação federal, mas, sobretudo de reconhecer, às pessoas em situação de união estável, ${ }^{20}$ algum estatuto jurídico.

Aliás, é sintomática a forma como a Constituição, bem como o Novo Código Civil se refurem ao instituto como sendo um reconhecimento, uma espécie de concessão excepcional do Estado para a doação de um estatuto jurídico a esta situação de fato oposta ao casamento civil; o art. 226, parágrafo $1^{\circ}$ da CF 88 preceitua que, para efeito de proteção do Estado, "é reconhecida a união estável entre o homem e a mulher como entidade familiar" e o art. 1.723 do Novo Código Civil afirma, na esteira da Carta Magna, que "É reconhecida como entidade familiar a união estável entre o homem e a mulher, configurada na convivência pública, contínua e duradoura e estabelecida com o objetivo de constituição de familia"

Apesar desta regulamentação. não parece ser a situação jurídica da família uma constante suficientemente regrada pelo sistema. Temas como o direito ao aborto (tratados como crime pelo sistema - no caso, art. 124 do Código Penal, com as exceções exclusivas do art. 128), como condição de realização da liberdade feminina, especialmente em face das recentes discussões e polêmicas provocadas pela liminares concedidas pelo ministro Marco Aurélio de Mello do Supremo Tribunal Federal sobre o direito sobre a vida do feto anecenfálico.

20. A opinião de Regina Beatriz, aqui registrada, constata este dado: "Para a advogada Regina Beatriz Tavares da Silva houve uma mudança nas relações conjugais, principalmente para as pessoas mais maduras: primeiramente, buscam um periodo de experiência em união estável, que é o casamento sem documento. sem a celebração perante o juiz de paz" (Casamento e familia. Entrevistas, Revista do Movimento do Ministério Público Democrático, ano I, n. 03, 2004, p. 20). E, também: "Muitos casais uptam. em época mais recente, por uniões de fato. Na realidade, em muitos casos não se trata de uma opção, mas de necessidade imposta pela situação de pobreza que desaconselha despesas com o matrimônio, aguardando tempos mais propícios para consagrar jurídica c/ou religiosamente a própria união. Há, no entanto, uniões de fato que não pensam em postergar, mas ignoram ou rejeitam o compromisso conjugal estável. Esquiva-se uma oficialização do vínculo, para evitar complicações de natureza jurídica, caso termine o interesse em partilhar a vida, ou pelo temor de que o vínculo sc torne uma amarra, que poderá limitar a liberdade individual" (Petrini. Pós-modernidade e familia: um itinerário de compreensão, 2003, p.75). 
Assim é que o Código Civil, de 2002, define de modo claro três instâncias diversas dos relacionamentos familiares: casamento; união estável; concubinato. Assim, pelo seu art. 1.565 C. Civil, define-se o casamento ("Pelo casamento, homem e mulher assumem mutuamente a condição de consortes, companheiros e responsáveis pelos encargos da família"), pelo seu art. 1.723, definese a união estável ("É reconhecida como entidade familiar, a união estável entre o homem e a mulher, configurada na convivência pública, contínua e duradoura e estabelecida com o objetivo de constituição de família"), e pelo seu art. 1.727, definese concubinato ("As relações não eventuais entre o homem e a mulher, impedidos de casar, constituem concubinato").

De fato, numa sucessão interminável, as modificações do setor são incapazes de responder à diversidade de reclamos que surgem pelos desafíos da vida contemporânea. Assim, são temas de permanente questionamento do setor: casamento monogâmico; prova judicial da violência doméstica; reparação civil por danos morais na separação e no divórcio; união estável; concubinato; casamento homossexual; família monoparental; casamento religioso com efeitos civis, etc. Portanto, a codificação não é mais capaz de conter toda tábua de direitos de um ramo mutável e inconstante como o do Direito de Família, frustrando-se a expectativa de reunificação do Direito sob a batuta de um único estatuto legal, daí o aparente caráter natimorto do "Novo" Código Civil, ${ }^{21}$ sintoma claro do caráter mais-do-que-fluido das estruturas fixas da modernidade (codificação, sistematização, racionalização, ordenação...) para o controle social (ineficazes na pós-modernidade).

\section{Conclusões}

Pode-se ter por termo desta investigação que o Direito de Familia vem refletindo. ao longo das últimas décadas, mudanças que são o retrato de que os próprios valores que fundam as relações intersubjetivas, e, especialmente de familia, estão vivendo re-conceituações, a ponto de confrontarem. colidirem ou exigirem mudanças do ordenamento juridico.

21. "O Código Civil -.. que ainda se costuma chamar de novo - nada traz sobre as familias monoparentais, apesar de $32 \%$ das familias do Brasil serem constituídas pela mãe e seus lilhos. ou surem familias chefiadas por mulheres" (DIAS, Maria Berenice. Privilégios masculinos, Artigo in http:/,www.intelligentiajuridica.com.br/v3/artigo4.html, Acesso em: 04.10.2004). 
O Direito de Família, dentre os diversos ramos do Direito Privado, parece, portanto, ser o melhor termômetro para a avaliação da avassaladora torrente de transformação das axiologias sociais, da afetação da estabilidade das instituições sociais, da descaracterização de padrões ético-axiológicos, de mudanças e alterações culturais que irromperam determinando a identificação do período pós-moderno.

Trata-se de um verdadeiro medidor que permite à análise jusfilosófica uma visão mais concreta dos efeitos e dos impactos das transformações sociais sobre os valores majoritários e centralizados das normas jurídicas de Estado (Moderno). Em função de uma análise que não escapa de uma preocupação culturalista, pode-se chegar a compreender os estremecimentos sofridos pelos ramos e setores mais sensíveis (porque mais humanos) da dogmática jurídica contemporânea.

Deve-se considerar especialmente o fato de que as mudanças na ética familiar - geradoras de mudanças jurídicas reiteradas e incessantes estão a demonstrar a transição da hegemonia axiológica (unidade) em direção a alternativas possiveis (pluralidade), bem como a acomodação dos valores sociais segundo novos parâmetros, diferentes daqueles conhecidos e aceitos até então. Sem dúvida, isto tudo levará o legislador a um exercício infatigável e incessante de debruçar-se sobre a realidade na tentativa de controla-la, ainda que todo o esforço seja em vão. Mais que tudo, estes tempos exigirão uma sobre-atenção do legislador sobre seus efeitos e sinais de mudança, portadores que são de sempre renovadas visões de mundo. Assim é que, estudadas as condições da vida pós-moderna, se consegue penetrar com maior segurança na análise das condições de possibilidade de um sistema jurídico realmente paramentado para atender às necessidades da vida hodierna, nem afeito a insistir na reinvenção do modelo anterior, e nem subserviente às condições do atual cenário axiológico.

\section{Bibliografia}

AZEVEDO, Álvaro Villaça. Estatuto da família de fato. São Paulo: Editora Jurídica Brasileira, 2001.

BAUMAN, Zygmunt. Amor liquido: sobre a fragilidade dos laços humanos. Rio de Janeiro: Jorge Zahar, 2004.

BITTAR, Carlos Alberto. Direito de familia. 2. ed. Rio de Janeiro: Forense Universitária, 1993. 
Os direitos da personalidade. 5. ed. rev. atual. aum. Eduardo C. B. Bittar. Rio de Janeiro: Forense Universitária, 2001.

BITTAR, Eduardo C. B. A crise do direito na pós-modernidade: um balanço jusfilosófico da experiência brasileira contemporânea. Tese (Livre-Docência). Departamento de Filosofia e Tcoria Geral do Direito. Faculdade de Direito. São Paulo: Universidade de São Paulo, 2004.

CAMPILONGO, Celso Fernandes. O direito na sociedade complexa. São Paulo: Max Limonad. 2000.

DIAS, Maria Berenice. Privilégios masculinos. Disponivel em: $<$ http://www.intelligentiajuridica.com.br/v3/artigo4.html>. Acesso em: 04.10.2004.

DINIZ. Maria Helena. O estado atual do biodireito. São Paulo: Saraiva, 2001.

EDITORIAL. Casamento e família. Entrevistas, Revista do Movimento do Ministério Público Democrático, ano 1, n. 03, 2004, p. 20-22.

FORBES, Jorge. Você quer o que deseja? São Paulo: Best Seller, 2003.

GRANDA, De Trazegnies. Postmodernidad y derecho. Colombia: Temis, 1993.

HARVFY, David. Condição pós-moderna: uma pesquisa sobre as origens da mudança cultural. Tradução de Adail Ubirajara Sobral; Maria Stela Gionçalves. São Paulo: Loyola. 2002.

JASPERS, Karl. Introdução ao pensamento filosófico. Tradução de Liônidas Hegenberg e Octanny Silveira da Mota. São Paulo: Cultrix. 1971.

LIPOVETSKY, Gilles. L'ère du vide: essais sur l'individualisme contemporain. Paris: Gallimard, 1983.

Barcarolla. 2004.

Os tempos hipermodernos. Tradução de Mário Villela. São Paulo:

LYOTARD, Jean-François. A condição pós-moderna. 2. ed. Tradução de José Bragança de Miranda. Lisboa: Gradiva, 1989.

PE'TRINI, João Carlos. Pós-modernidade e familia: um itinerário de compreensão. Bauru: EDUSC, 2003.

SARLO, Beatriz. Cenas da vida pós-moderna: intelectualismo, arte e videocultura na Argentina. 2. ed. Tradução de Sérgio Alcides. Rio de Janeiro: UFRJ, 2000.

SILVA, Regina Beatriz Tavares da. Reparação civil na separação e no divórcio. São Paulo: Saraiva, 1999.

SILVA, Regina Beatriz Tavares da. A dignidade da pessoa humana: princípio fundamental de direito constitucional e de direito de família, in Estudos de Direito de 
Autor, Direito da personalidade, Direito do consumidor e danas morais, Estudos em homenagem a Carlos Alberto Bittar (Eduardo C. B. Bittar; Silmara Juny Chinelato, orgs.), Rio de Janeiro, Forense Universitária, p. 107-120, 2003.

SIQUEIRA, Holgonsi Soares G. A pós-modernidade: conseqüência da revolução gnóstica e igualitária. Disponível: http://www.angelfire.com/id/Viotti/PosModern.html. Acesso em: 25.08.2002.

VENOSA, Silvio de Salvo. Novo Código ('ivil. São Paulo: Atlas, 2002. 